\title{
I!:
}

\section{ESTUDO DO COMPORTAMENTO DE MISTURAS ASFÁLTICAS MODIFICADAS COM ADIÇÃO DE BORRACHA MOÍDA DE PNEUS}

\author{
STUDY OF THE BEHAVIOUR OF MODIFIED ASPHALT MIXTURES WITH \\ ADDITION OF GROUND RUBBER TIRES
}

\author{
${ }^{1}$ Bruno de Oliveira Rocha \\ ${ }^{2}$ Ronaldo Feu Rosa Pacheco \\ ${ }^{1}$ Instituto Federal do Espírito Santo (IFES). E-mail: brunorocha.eng@ outlook.com \\ ${ }^{2}$ Instituto Federal do Espírito Santo (IFES). E-mail: ronaldo@ifes.edu.br \\ *Autor de correspondência
}

Artigo submetido em 04/11/2020, aceito em 06/09/2021 e publicado em 26/10/2021.

Resumo: Objetiva-se, com este trabalho, avaliar o desempenho mecânico e volumétrico de uma mistura asfáltica densa com diferentes teores de borracha moída pneumática em substituição parcial do agregado miúdo. A borracha inserida nas misturas passou a fazer parte da composição granulométrica junto aos demais agregados pétreos. Esse processo é conhecido como "processo seco". Realizam-se, no laboratório da usina de asfalto localizada no município de Cariacica-ES, as misturas, as quais são comparadas com uma mistura de controle sem adição de borracha, dosada de forma tradicional. Obteve-se o desempenho mecânico das misturas por meio de ensaios de resistência à tração e da estabilidade Marshall. $\mathrm{O}$ aumento do teor da borracha na mistura asfáltica densa altera o desempenho estrutural das misturas quando comparadas à mistura sem borracha. A inclusão da borracha na mistura não alterou, de forma significativa, a composição granulométrica dos agregados, quando comparada àquela sem borracha. Verifica-se que a mistura de $1 \%$ de borracha adicionada em peso apresenta os melhores resultados para as propriedades mecânicas. Os resultados mostram que, quanto maior a quantidade de borracha, a resistência à tração e estabilidade diminuem, porém, em níveis controlados, aumentam consideravelmente a resistência à fadiga, a resistência à deformação permanente e melhoram a flexibilidade a baixas temperaturas. Assim, conclui-se que o uso da borracha de pneus na pavimentação asfáltica contribui para minimizar os problemas de destinação final de pneus inservíveis $\mathrm{e}$, ao mesmo tempo, melhora a deformação permanente e a flexibilidade a baixas temperaturas.

Palavras-chave: asfalto-borracha; processo seco; misturas asfálticas; reciclagem; pavimentos.

\begin{abstract}
This work aims to evaluate the mechanical and volumetric performance of a dense asphalt mixture with different levels of pneumatic ground rubber in partial replacement of the small aggregate. The rubber inserted in the mixtures became part of the particle size composition along the other stone aggregates. This process is known as "dry process". The mixtures take place in the laboratory of the asphalt plant, located in Cariacica-ES, and are compared with a control mixture without adding rubber, dosed in a traditional way. The mechanical performance of the mixtures was obtained through tensile strength and Marshall stability tests. Increasing the rubber content in the dense asphalt mixture changes the structural performance of the mixtures when compared to the mixture without rubber. The inclusion of rubber in the mixture did not significantly change the particle size composition of the aggregates, when compared to the rubber-free mixture. It is verified that the mixture of $1 \%$ rubber added in weight presents the best results for the mechanical properties. The results show that the
\end{abstract}


greater the amount of rubber the tensile strength and stability decrease, but in controlled levels considerably increase fatigue resistance, permanent strain resistance and improve flexibility at low temperatures. It is concluded that the use of tire rubber in asphalt paving contributes to minimize the problems of final disposal of unserviceable tires and, at the same time, improves permanent deformation and flexibility at low temperatures.

Keywords: asphalt-rubber; dry process; asphalt mixtures; recycling; pavements.

\section{INTRODUÇÃO}

De acordo com IBAMA (2017), em 2016, foram produzidas $966.343,70$ toneladas de pneus no Brasil. Alguns países veem, com grande interesse, a utilização da borracha reciclada nas misturas asfálticas, pois é latente a preocupação com a preservação dos recursos naturais e, consequentemente, o reuso de materiais que outrora eram inservíveis (SALINI, 2000).

Segundo Wang et al. (2018), as emissões de $\mathrm{O}_{2}, \mathrm{~N}_{2}, \mathrm{CO}_{2}, \mathrm{NO}_{\mathrm{x}} \mathrm{e} \mathrm{SO}_{2}$ na produção de misturas asfálticas com borracha foram um pouco semelhantes às do asfalto misturado a quente (variando de $+0,5 \%$ a $-10,7 \%$ ). No entanto, as emissões de $\mathrm{CO}$ e $\mathrm{CH}_{4}$ foram muito mais baixas, ou seja, $-39,7 \%$ e $-61,7 \%$, respectivamente.

As camadas asfálticas são submetidas às repetidas cargas impostas pelo tráfego, e, após um período de tempo, esses carregamentos causam a perda de rigidez dessas camadas, resultando na fadiga, que é um dos principais tipos de deterioração que ocorrem nos pavimentos flexíveis. Isso acontece por causa da baixa resistência à tração do asfalto misturado a quente. $\mathrm{O}$ aumento da resistência à fadiga $\mathrm{e}$ maior resistência ao desgaste e ao envelhecimento é um dos potenciais benefícios da incorporação da borracha à mistura asfáltica. Além disso, pode-se destacar o aumento da flexibilidade a baixas temperaturas, o aumento da resistência à deformação permanente a altas temperaturas, o aumento da resistência à fadiga e maior resistência ao desgaste e ao envelhecimento (FHWA, 1993).

No estado do Espírito Santo, é recente a utilização da borracha de pneu como alternativa na fabricação asfáltica, pois existem poucas empresas especializadas em produzir esse material. Essa situação motivou o surgimento da seguinte questão problema: É possível estudar o comportamento de misturas asfálticas modificadas com adição de borracha moída de pneus?

A relevância deste estudo consiste em difundir o uso da técnica no estado do Espírito Santo, já que os órgãos estaduais e municipais não incluem em seus projetos de pavimentação o uso do asfalto ecológico. $\mathrm{O}$ estado possui empresas especializadas na moagem de pneus e várias usinas de asfalto, o que facilita o uso da borracha moída de pneus na mistura asfáltica.

Os benefícios ambientais são inúmeros, visto que as carcaças de pneus usados descartados a céu aberto contribuem para o aumento da proliferação de insetos e roedores, que são vetores de várias doenças, além de serem incompressíveis e de degradação lenta, ocupando muito espaço nos aterros sanitários.

O trabalho de pesquisa seguiu a hipótese de que é possível desenvolver um estudo do comportamento de misturas asfálticas modificadas com a adição de borracha moída de pneus em um projeto piloto no estado do Espírito Santo.

Portanto, o principal objetivo do estudo é encontrar misturas betuminosas para verificar os efeitos da substituição de parte do agregado miúdo por borracha moída para misturas asfálticas densas, comparando com misturas asfálticas convencionais.

Avalia-se o desempenho mecânico e volumétrico da mistura asfáltica na 
substituição parcial do agregado miúdo por borracha moída de pneus, nos teores de $1 \%$, $2 \%$ e $3 \%$ em relação ao peso total da mistura, respeitando o tempo mínimo de digestão da borracha nas misturas asfálticas, sendo um projeto piloto no estado do Espírito Santo. Os parâmetros mecânicos avaliados foram a estabilidade e a resistência à tração.

\section{REFERENCIAL TEÓRICO}

A incorporação da borracha em misturas asfálticas pelo processo seco foi desenvolvida na Suécia, na década de 1960, e patenteada com o nome de Rubit (EPPS 1994 apud BERTOLLO et al., 2002, p. 68). Nos Estados Unidos, foi patenteado o método PlusRide. A crescente preocupação com questões ambientais, expressa também por leis que regulamentam o emprego de pneus em misturas asfálticas, motivou mais estudos sobre o tema. Surgiram novas tecnologias desde então, como a tecnologia genérica em 1989.

Hemant et al. (2019) constataram que os benefícios das misturas asfálticas modificadas com borrachas ocorreram mais em estradas de alta velocidade, ao mesmo tempo, em que tiveram um impacto menor em estradas de baixa velocidade. $\mathrm{O}$ asfalto é um material viscoelástico dependente da frequência. Isso significa que ele reagirá como um material forte sob carregamento de alta frequência (alta velocidade) e reagirá como material relativamente fraco sob carregamento de baixa frequência (baixa velocidade).

Segundo Setyawan et al. (2016), a adição de borracha fragmentada em asfalto de mistura quente de superfície fina leva ao aumento do valor da Estabilidade Marshall, fluência e assim obtendo melhor intertravamento e ligação entre o agregado e o betume. Além disso, a partir da análise de correlação entre a porcentagem de substituição do agregado por borracha fragmentada e o conteúdo ideal de betume notou-se a redução teor ideal de betume, diminuindo assim o uso de betume de petróleo convencional e tornando-se a construção de infraestrutura ambientalmente correta.

\subsection{ESTUDOS DE CASO NO BRASIL}

Sartori e Luvizão (2014) desenvolveram em laboratório seis misturas asfálticas pelo processo seco, sendo uma sem adição de borracha (referência) e outras cinco com $(1 \% ; 1,5 \% ; 2 \% ; 2,5 \%$ e $3 \%)$ de borracha, respectivamente. A faixa "C" DNIT NORMA 031 (DEPARTAMENTO NACIONAL DE INFRAESTRUTURA E TRANSPORTES; 2006) foi utilizada para elaboração das misturas. Os resultados dos ensaios de todos os traços dosados ficaram dentro dos parâmetros da norma DNIT $031 / 2006$. A mistura com $1 \%$ de borracha reciclada foi escolhida como a ideal por ser a mais econômica, pois apresentou o menor consumo de betume, tendo em vista que o cimento asfáltico de petróleo (CAP) é o insumo de maior custo da mistura. $\mathrm{O}$ teor de ligante ficou em $6,15 \%$, volume de vazios $4,9 \%$, vazios do agregado mineral $19,45 \%$, relação betume vazios $75 \%$ e estabilidade de 700 kgf. Ressalta-se que a escolha do traço se deu também pelo fato de se reciclar um material outrora inservível, o que é um enorme benefício ao meio ambiente. Porém, a mistura de referência ficou com menor teor de betume e maior estabilidade do que todos os traços elaborados.

Cogo (2017) fez um experimento em laboratório utilizando borracha moída com granulometria individual de diâmetro máximo de 4,75 $\mathrm{mm}$ reciclada de pneus em uma mistura asfáltica. Quanto à granulometria da mistura, foi utilizada a faixa "C" do DNIT. Os percentuais de borracha utilizados no processo foram de $1 \%, 3 \%$ e $5 \%$ em substituição ao agregado miúdo. $\mathrm{O}$ teor ótimo de betume encontrado foi de $7,1 \%$, e a autora tomou como parâmetro o volume de vazios que, de acordo com a norma do DNIT 031/2006, deve ficar entre $3 \%$ e $5 \%$ para a faixa "C". As misturas com teores de borracha de $3 \%$ e 
5\% ficaram com volume de vazios muito elevados, e a autora concluiu que tal fenômeno se dá devido ao fato de a borracha ser um material elástico, ou seja, ela volta à forma inicial, o que acabou comprometendo negativamente no que se refere à densificação dos corpos de prova. Isso acarretou em não ser possível determinar os teores ótimos de betume.

Foram realizados, em todas as misturas, os ensaios de resistência à tração e módulo de resiliência. À medida que se aumentou a quantidade de borracha, os valores do módulo e resistência à tração diminuíram e a mistura com $1 \%$ de borracha obteve o melhor desempenho. Sendo assim, observou-se como a mais adequada para o uso na pavimentação asfáltica.

\section{PROCESSOS METODOLÓGICOS: MATERIAIS E MÉTODOS}

Para o estudo, foram obtidas amostras de agregados pétreos, borracha moída e ligante asfáltico convencional. Esses materiais foram utilizados nos seguintes ensaios de laboratório: granulometria e densidade real dos agregados e da borracha moída, absorção, sanidade, equivalente de areia e abrasão "Los Angeles" dos agregados pétreos. Quanto ao ligante asfáltico, foram feitos os ensaios de viscosidade Brookfield, ponto de fulgor, penetração, ponto de amolecimento e espuma, além do índice de susceptibilidade térmica.

Em relação às misturas asfálticas, foram realizados os ensaios pertinentes ao método Marshall listados na norma DNIT 031/2006. Os ensaios foram feitos no laboratório de solos e betume do Instituto Federal do Espírito Santo, campus Vitória, e no laboratório de solos e asfalto da empresa Betume Grande Vitória na cidade de Cariacica-ES.

\subsection{CARACTERIZAÇÃO DOS MATERIAIS}

\subsubsection{Agregados}

A coleta dos agregados obedeceu aos requisitos da norma Coleta de Amostras de Agregados do DNER-PRO 120/97.

$\mathrm{O}$ agregado mineral de origem gnáissica utilizado neste trabalho foi coletado na Pedreira Brasitália, na cidade de Cariacica-ES. Para compor a mistura, foi necessária a coleta de três tipos de agregados: Brita $01-19 \mathrm{~mm}$, brita $0-12,7$ $\mathrm{mm}$ e pó de pedra $-4,8 \mathrm{~mm}$ para atender à faixa granulométrica utilizada no projeto; a “B” do DNIT NORMA 031/2006.

Procedeu-se à redução dos agregados para obter a quantidade mínima para os ensaios das misturas betuminosas, realizando a separação em partes homogêneas da amostra de cada agregado coletado de acordo com a norma do (DEPARAMENTO NACIONAL DE ESTRADAS DE RODAGEM), DNERPRO 199/96. Utilizou-se o separador mecânico de amostras com aberturas condizentes com a granulometria de cada material de acordo com o método utilizado.

\section{- GRANULOMETRIA}

Os ensaios de granulometria dos agregados foram feitos conforme a norma DNER-ME 083/98, utilizando-se de peneiras de malha quadrada e de aberturas que obedecem a uma sequência específica estabelecida pela faixa " $\mathrm{B}$ " da norma DNIT 031/2006.

\section{- MASSA ESPECÍfICA E ABSORÇÃO}

Foram feitos os ensaios de absorção e da densidade real dos agregados graúdos, miúdo e do material finamente pulverizado, conforme as normas DNER-ME 081/98, DNER-ME 084/95， DNER-ME 085/94, respectivamente.

A massa específica não possui limites nas especificações técnicas, ela é usada apenas para o cálculo de massa específica efetiva dos agregados. Segundo Bernucci et al. (2008), deve-se considerar, para efeito de dosagem das misturas asfálticas, a massa específica efetiva para 
agregados que possuem absorção inferior a $2 \%$, na qual o volume de poros é pequeno, sendo possível, assim, calcular o volume efetivo do agregado.

\section{- ABRASÃO "LOS ANGELES"}

Os agregados pétreos estão sujeitos a quebras e abrasão durante o processo de manuseio e execução dos revestimentos asfálticos; portanto, devem ser utilizados agregados que sejam capazes de resistir às fraturas, quebra, degradação e desintegração. Para medir a resistência dos agregados, foi feito o ensaio de abrasão "Los Angeles" de acordo com a norma DNER-ME 035/98.

\section{- DURABILIDADE/SANIDADE}

Os agregados podem sofrer desintegração química por meio de intempéries, como o sol e a chuva. $\mathrm{O}$ ensaio de sanidade/durabilidade simula se o agregado é mais ou menos susceptível a essa desintegração, quando submetido a alguns ciclos de imersão em uma solução saturada de sulfato de sódio ou magnésio, com duração de 16 a 18 horas à temperatura de $21^{\circ} \mathrm{C}$ e depois secada em estufa durante 6 horas. Os procedimentos desse ensaio seguiram a norma DNER-ME 089/94.

\section{- EQUIVALENTE DE AREIA}

A proporção relativa de materiais tipo argila em amostras de agregados miúdos pode ser detectada pelo ensaio de equivalente de areia. $\mathrm{O}$ ensaio foi feito de acordo com a norma DNER-ME 054/97.

\section{- LAMELARIDADE}

A geometria das partículas dos agregados influencia diretamente na resistência ao cisalhamento das misturas asfálticas, na trabalhabilidade e também altera a energia de compactação necessária para atingir a densidade máxima in situ. As partículas mais chatas e alongadas são mais susceptíveis à segregação e a quebras durante a compactação, enquanto as mais cúbicas proporcionam melhor intertravamento entre os grãos. $\mathrm{O}$ ensaio de lamelaridade foi feito na brita $01-19 \mathrm{~mm}$ e na brita $0-12,7 \mathrm{~mm}$, com a placa de lamelaridade conforme a norma do DEPARTAMENTO AUTÔNOMO DE ESTRADAS DE RODAGEM, DAER/RSEL 108/01.

\subsubsection{Cimento asfáltico de petróleo (CAP)}

O CAP utilizado nas misturas desta pesquisa foi o 30/45, fornecido pela refinaria Duque de Caxias REDUC/Petrobrás no estado do Rio de Janeiro.

O acondicionamento do CAP utilizado nas dosagens foi feito em um recipiente com tampa e o interior devidamente limpo, para evitar contaminação por poeira e conservar suas propriedades ao longo do desenvolvimento do trabalho.

Abaixo são listados todos os ensaios de caracterização do ligante utilizado neste estudo.

\section{- PENETRAÇÃO}

$\mathrm{O}$ ensaio de penetração consiste em medir a consistência do ligante asfáltico. A penetração expressa, em décimos de milímetros, a profundidade que uma agulha com carga-padrão de $100 \mathrm{~g}$ penetra em uma amostra de CAP em uma cápsula de volume padronizado a uma temperatura de $25^{\circ} \mathrm{C}$ durante cinco segundos. Esse ensaio foi feito de acordo com a norma DNIT 155/2010 (BERNUCCI et al., 2008).

\section{- PONTO DE AMOLECIMENTO}

O ensaio de determinação do ponto de amolecimento pelo método do anel e bola foi feito conforme a norma DNIT $131 / 2010$ - ME, que consiste no registro da temperatura em que o ligante e a esfera tocam o fundo do béquer de vidro após o aquecimento.

\section{- VISCOSIDADE BROOKFIELD}

$\mathrm{O}$ ensaio de viscosidade Brookfield foi feito conforme a norma da ASSOCIAÇÃO BRASILEIRA DE 
NORMAS TÉCNICAS, NBR 15184/2004. Esse ensaio consiste na medição da viscosidade dinâmica de fluidos. O spindle é mergulhado no ligante e, após, rotacionado de forma constante e uniforme, enquanto o aparelho mede a força necessária para vencer a resistência do material. Com os resultados desse ensaio, foi possível determinar a temperatura de usinagem e compactação da mistura Brookfield (BERNUCCI et al., 2008).

\section{- $\quad$ PONTO DE FULGOR}

O ensaio do ponto de fulgor tem por finalidade verificar a segurança do manuseio do CAP durante o transporte, a estocagem e a usinagem da massa asfáltica. Ele indica a menor temperatura em que os vapores provenientes do ligante asfáltico inflamam na presença de uma chama. $O$ valor do ponto de fulgor deve ser superior a $235^{\circ} \mathrm{C}$ segundo a norma NBR 11341:2014.

\section{- ESPUMA}

Para a obtenção do resultado do ensaio de espuma, o ligante deve ser aquecido até $177^{\circ} \mathrm{C}$, quando pode ser verificado se apresenta essa espuma. $\mathrm{O}$ ensaio é apenas qualitativo e, no caso do ligante utilizado, teve resultado satisfatório. A sigla utilizada para o registro da informação é a abreviação "NESP". Isso significa que o CAP não espumou durante o aquecimento (BERNUCCI et al., 2008).

\section{- IINDICE DE SUSCEPTIBILIDADE TÉRMICA}

Após a obtenção dos resultados dos ensaios de penetração e do ponto de amolecimento, foi possível calcular o índice de susceptibilidade térmica. A norma DNIT 095/2006 admite a variação do IST entre 1,5 e $+0,7$. Quando os valores encontrados são levemente positivos, mostra-se que o ligante é mais indicado para regiões mais quentes e os valores negativos indicados para regiões mais frias. Valores acima de $+0,7$ indicam que o CAP sofreu um processo de oxidação em seu manuseio, ou seja, a mistura asfáltica tende a ser pouco flexível e susceptível a fadiga e trincamentos. Valores de IST abaixo de -1,5 tenderão a produzir uma mistura de baixa resistência ao cisalhamento, o que, consequentemente, acarretará uma trilha de roda (BERNUCCI et al., 2008).

\section{- DENSIDADE DO CAP}

A finalidade da obtenção da densidade do CAP é a conversão de massas em volumes para a utilização nos cálculos de teor de ligante de projeto das misturas asfálticas. $\mathrm{O}$ ensaio foi realizado conforme a norma ABNT NBR 6296.

\subsubsection{Borracha moída}

A borracha moída utilizada nas dosagens foi coletada no IFES campus Vitória-ES, originária da empresa RACRI INDÚSTRIA DE RECICLAGEM LTDA., situada na cidade de Betim-MG, e colocada em saco plástico vedado para evitar a contaminação por poeira e umidade.

Não existe norma específica para caracterizar a borracha. $\mathrm{O}$ projeto foi elaborado mediante as informações das literaturas existentes sobre o "processo seco". As características necessárias à inserção da borracha nas dosagens são a granulometria e a massa específica real.

A borracha granular utilizada neste estudo possui granulometria fina de diâmetro máximo de 2,4 mm, valendo-se da mesma série de peneiras usadas no agregado.

$\mathrm{Na}$ elaboração da composição granulométrica das misturas experimentais, a borracha foi considerada como mais um agregado da mistura e substituiu parte do agregado miúdo. A diferença de massa específica entre eles não foi levada em conta, a substituição foi feita utilizando-se do parâmetro de massa e se manteve o arranjo granulométrico da mistura de controle. A faixa utilizada foi a "B" da norma 031/2006 do DNIT. 
A densidade da borracha foi feita por meio de deslocamento de fluído, utilizandose de um béquer e $20 \mathrm{ml}$ de querosene a $25^{\circ} \mathrm{C}$ e $5 \mathrm{ml}$ de borracha. Não existe norma específica para calcular a densidade de borracha moída. Esse método foi utilizado por ser muito simples e preciso (SALINI, 2000).

\subsubsection{Método Marshall}

norma $\begin{array}{lr}\text { Utilizou-se o Método } & \text { Marshall da } \\ \text { DNER-ME } & \mathbf{0 4 3}\end{array}$
(DEPARTAMENTO NACIONAL DE ESTRADAS DE RODAGEM; 1995) para a obtenção dos parâmetros da dosagem do concreto asfáltico.

Após a realização da granulometria individual dos agregados, eles foram submetidos a uma composição granulométrica de partida, para, posteriormente, enquadrá-los nos limites da faixa granulométrica da faixa " $B$ " da norma DNIT 031/2006. Finalizadas as tentativas de enquadramento, é nesse momento que ficam estabelecidos os percentuais de cada agregado que compõe a mistura asfáltica. Foram moldados 48 corpos de prova, sendo 12 corpos de prova por dosagem e quatro teores de betume para cada três corpos de prova. Os corpos de prova foram pesados 72 horas após a moldagem para a obtenção dos parâmetros mecânicos e volumétricos das misturas.

A borracha e os agregados foram pesados para compor grupos de três corpos de prova por vez, sendo uma mistura por recipiente, e colocados em estufa junto com os moldes a uma temperatura de $165^{\circ} \mathrm{C}$ por um período de três horas. Depois de passado esse tempo, a temperatura da mistura foi verificada com termômetro de vidro devidamente calibrado. O ligante asfáltico foi levado à estufa previamente aquecido em fogareiro, em um recipiente com tampa, por três horas, à temperatura de $150^{\circ} \mathrm{C}$.

Os moldes usados na moldagem dos corpos de prova ficaram em estufa para serem aquecidos com os agregados, como forma de não comprometer a temperatura de compactação da massa asfáltica.

Passadas três horas de aquecimento do ligante e da mistura dos agregados com borracha, eles foram retirados para o processo de mistura e misturados de forma manual, até o completo envolvimento do ligante asfáltico nas partículas dos agregados e da borracha.

As misturas foram feitas uma a uma, com o peso de aproximadamente 1.200 gramas cada uma e colocadas em recipientes de alumínio, levados à estufa a uma temperatura de $150^{\circ} \mathrm{C}$, onde permaneceram por duas horas, para simular o processo de digestão da borracha e envelhecimento do ligante durante o processo de usinagem, transporte $\mathrm{e}$ aplicação da mistura na pista.

Passadas as duas horas em estufa, as misturas foram sendo colocadas no molde, acomodadas com 15 golpes de espátula nas laterais do cilindro e 10 golpes no centro. Feito esse processo, foram aplicados 75 golpes com o soquete Marshall em cada face do corpo de prova. Após 24 horas, os corpos de prova foram extraídos do cilindro e devidamente enumerados.

Depois de extraídos e identificados, fez-se necessária a medição do diâmetro e da média de quatro alturas dos corpos de prova para a correção da estabilidade e cálculo da resistência à tração.

Determina-se a massa específica aparente da mistura asfáltica compactada em laboratório de acordo com a norma DNER-ME 117/94. A massa específica é definida como a relação entre a massa seca ao ar do corpo de prova compactado e a diferença entre a massa seca do corpo de prova pela massa do corpo de prova submerso. Para cada um dos 48 corpos de prova moldados, fez-se necessário o cumprimento desse passo a passo, para a obtenção dos resultados de massa específica aparente.

\section{RESULTADOS E DISCUSSÃO}


Neste capítulo, serão apresentados todos os resultados de caracterização dos materiais constituintes das misturas dosadas neste estudo.

\subsection{RESULTADOS DA CARACTERIZAÇÃO DOS AGREGADOS}

Nesta seção, são apresentados os resultados da caracterização dos agregados utilizados nas dosagens das misturas asfálticas.

\subsubsection{Granulometria}

Tabela 01: Faixa granulométrica dos agregados com e sem borracha

\begin{tabular}{|c|c|c|c|c|c|c|c|}
\hline \multicolumn{8}{|c|}{ COMPOSIÇÃO GRANULOMÉTRICA DAS MISTURAS } \\
\hline Polegada & Milímetros & \multirow{2}{*}{$\begin{array}{c}\text { Granulometria } \\
\text { das Mistura de } \\
\text { Referência - Sem } \\
\text { Borracha }\end{array}$} & \multicolumn{3}{|c|}{$\begin{array}{c}\text { Granulometria das Misturas com Borracha } \\
\text { Moída }\end{array}$} & \multicolumn{2}{|c|}{$\begin{array}{l}\text { Limites da Faixa "B" do } \\
\text { DNIT - NORMA 031/2006 }\end{array}$} \\
\hline & & & $1 \%$ & $2 \%$ & $3 \%$ & Mínimo & Máximo \\
\hline $11^{1 / 2 "}$ & 38,1 & $100,0 \%$ & $100,0 \%$ & $100,0 \%$ & $100,0 \%$ & $100,0 \%$ & $100,0 \%$ \\
\hline $1 "$ & 25,4 & $100,0 \%$ & $100,0 \%$ & $100,0 \%$ & $100,0 \%$ & $95,0 \%$ & $100,0 \%$ \\
\hline $3 / 4 "$ & 19,1 & $100,0 \%$ & $100,0 \%$ & $100,0 \%$ & $100,0 \%$ & $80,0 \%$ & $100,0 \%$ \\
\hline $3 / 8$ & 9,5 & $65,0 \%$ & $65,0 \%$ & $65,0 \%$ & $65,0 \%$ & $45,0 \%$ & $80,0 \%$ \\
\hline$n^{\circ} 4$ & 4,8 & $43,1 \%$ & $43,1 \%$ & $43,1 \%$ & $43,1 \%$ & $28,0 \%$ & $60,0 \%$ \\
\hline $\mathrm{n}^{\circ} 10$ & 2,0 & $34,7 \%$ & $34,8 \%$ & $35,0 \%$ & $35,1 \%$ & $20,0 \%$ & $45,0 \%$ \\
\hline$n^{\circ} 40$ & 0,42 & $19,2 \%$ & $18,9 \%$ & $18,6 \%$ & $18,2 \%$ & $10,0 \%$ & $32,0 \%$ \\
\hline $\mathrm{n}^{\circ} 80$ & 0,18 & $10,8 \%$ & $10,5 \%$ & $10,3 \%$ & $10,1 \%$ & $8,0 \%$ & $20,0 \%$ \\
\hline $\mathrm{n}^{\circ} 200$ & 0,074 & $5,3 \%$ & $5,1 \%$ & $5,0 \%$ & $4,9 \%$ & $3,0 \%$ & $8,0 \%$ \\
\hline
\end{tabular}

Fonte: Elaborada pelo autor (2019).
$\mathrm{Na}$ Tabela 01, apresenta-se a composição granulométrica da mistura de referência e das misturas experimentais com $1 \%, 2 \%$ e $3 \%$ de borracha moída de pneus. faixas de trabalho ficaram dentro dos limites da faixa "B" da norma DNIT 031/2006. A curva granulométrica apresentada na cor preta no gráfico 01 é da mistura de referência, porém a adição de borracha altera a curva de forma pouco significativa e praticamente não altera a estrutura da mistura. Todas as granulometrias e as respectivas 
Gráfico 01: Composição granulométrica

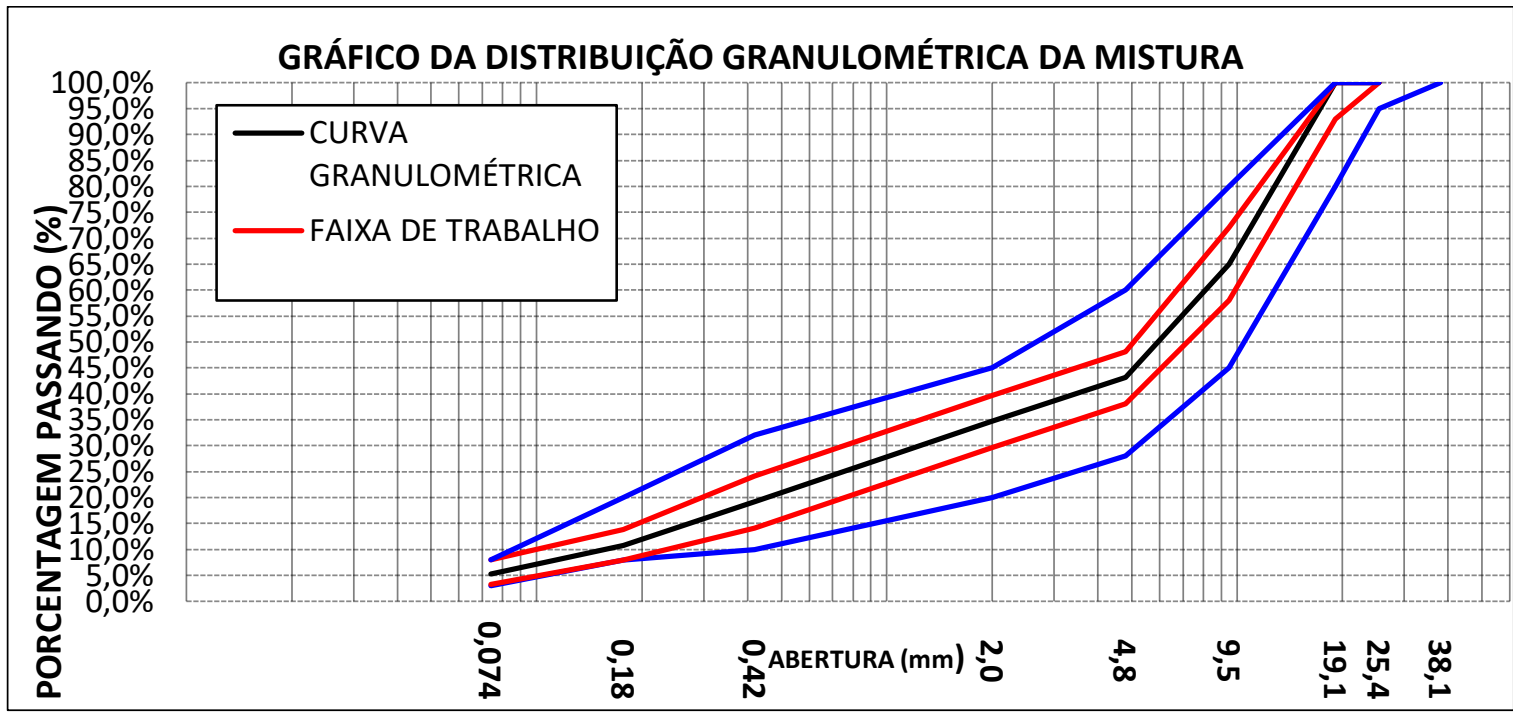

Fonte: Elaborado pelo autor (2019).

\subsubsection{Massa específica e absorção}

Abaixo, segue a tabela 02 com os resultados e as normas aplicadas a cada ensaio. Os resultados da massa específica são utilizados na dosagem das misturas asfálticas para o cálculo da massa específica efetiva dos agregados. Para que se utilize desse método, eles devem possuir uma absorção de no máximo $2 \%$, pois assim é possível calcular o volume efetivo do agregado.

Tabela 02: Massa específica e absorção

\begin{tabular}{|c|c|c|c|}
\hline Material & $\begin{array}{c}\text { Absorção } \\
(\%)\end{array}$ & $\begin{array}{c}\text { Massa específica } \\
\mathrm{g} / \mathrm{cm}^{3}\end{array}$ & Norma \\
\hline Brita 01 & 0,45 & 2,840 & $\begin{array}{c}\text { DNER-ME } \\
081 / 98 \\
\text { DNER-ME }\end{array}$ \\
\hline Brita 0 & 0,67 & 2,858 & $\begin{array}{c}\text { 081/98 } \\
\text { DNER-ME }\end{array}$ \\
\hline $\begin{array}{l}\text { Pó de Pedra } \\
\text { Finamente }\end{array}$ & - & 2,840 & $\begin{array}{c}\text { 084/95 } \\
\text { DNER-ME }\end{array}$ \\
\hline Pulverizado & - & 2,810 & $085 / 94$ \\
\hline
\end{tabular}

\subsubsection{Abrasão "Los Angeles"}

Os resultados do ensaio de abrasão "Los Angeles" da brita $01-19 \mathrm{~mm}$ e brita 0 - $12,7 \mathrm{~mm}$ foram, respectivamente, $41 \% \mathrm{e}$
$45 \%$ de acordo com a tabela 03. Ambos ficaram dentro da especificação do DNIT

031/2006, que recomenda o uso de agregados com até $50 \%$ de abrasão.

Tabela 03: Abrasão “Los Angeles”

\begin{tabular}{|c|c|c|c|c|}
\hline $\begin{array}{c}\text { Identificação } \\
\text { das } \\
\text { amostras }\end{array}$ & $\begin{array}{c}\text { Graduação } \\
\text { utilizada }\end{array}$ & $\begin{array}{c}\text { Perda de } \\
\text { massa } \\
(\%)\end{array}$ & $\begin{array}{c}\text { Limite } \\
\text { máximo } \\
\text { de perda } \\
\text { de } \\
\text { massa } \\
(\%) \text { - } \\
\text { DNIT } \\
\text { 031/2006 }\end{array}$ & $\begin{array}{l}\text { Método de } \\
\text { Ensaio }\end{array}$ \\
\hline $\begin{array}{c}\text { Amostra de } \\
\text { Brita } 0\end{array}$ & $\mathrm{C}$ & 45 & \multirow{2}{*}{$<50$} & \\
\hline $\begin{array}{c}\text { Amostra de } \\
\text { Brita } 1\end{array}$ & B & 41 & & $\begin{array}{c}\text { DNER- } \\
\text { ME 035/98 }\end{array}$ \\
\hline
\end{tabular}

Fonte: Elaborada pelo autor (2019).

\subsubsection{Sanidade/durabilidade}

Verifica-se, na tabela 04, que a perda de massa de $0,88 \%$ da brita $01-19 \mathrm{~mm}$, utilizada na pesquisa, é inferior ao limite exigido pela norma DNIT 031/2006 que é de $12 \%$. 
Tabela 04: Durabilidade

\begin{tabular}{lcc}
\hline Material & $\begin{array}{c}\text { Perda de massa (\%) } \\
\text { Sulfato de sódio }\end{array}$ & $\begin{array}{c}\text { NORMA DNIT } \\
\mathbf{0 3 1 / 2 0 0 6}\end{array}$ \\
\hline Brita 01 & 0,88 & $<12$ \\
\hline
\end{tabular}

Fonte: Elaborada pelo autor (2019).

\subsubsection{Equivalente de areia}

$\mathrm{O}$ resultado do equivalente de areia foi $66,2 \%$, conforme a tabela 05 ; logo, está dentro da norma DNIT 031/2006, que determina ser igual ou superior a $55 \%$ o valor do equivalente de areia.

Tabela 05: Equivalente de areia

\begin{tabular}{cccc}
\hline Proveta no $^{\mathbf{0}}$ & $\mathbf{1}$ & $\mathbf{2}$ & $\mathbf{3}$ \\
\hline h1 & 13,5 & 13,07 & 13,12 \\
h2 & 8,85 & 8,71 & 8,7 \\
Resultado (\%) & 65,6 & 66,6 & 66,3 \\
\hline Média (\%) & 66,2 \\
\hline Fonte: Elaborada pelo autor (2019).
\end{tabular}

Fonte: Elaborada pelo autor (2019).
Os resultados da lamelaridade são de $17 \%$ e $12 \%$, respectivamente, da brita 01 e da brita 0 . Conforme a tabela 06 , ela está dentro da norma DAER/RS-EL 108/01, que determina ser no máximo a 50\%; portanto, os agregados utilizados no projeto apresentam boa cubicidade.

Tabela 06: Lamelaridade

\begin{tabular}{|c|c|c|}
\hline Materiais & Resultado encontrado & Norma \\
\hline Brita $01-19 \mathrm{~mm}$ & $12 \%$ & \\
\hline Brita $0-12,7 \mathrm{~mm}$ & $17 \%$ & DAER/RS-EL \\
& $108 / 01$ \\
\hline
\end{tabular}

Fonte: Elaborada pelo autor (2019).

\subsection{CIMENTO ASFÁLTICO DE PETRÓLEO (CAP)}

$\mathrm{Na}$ tabela 07, apresentam-se os resultados da caracterização do ligante asfáltico utilizado neste estudo. Verifica-se que todos os valores encontrados estão dentro das exigências da norma do DNIT 095/2006.

\subsubsection{Lamelaridade}

Tabela 07: Caracterização do CAP

\begin{tabular}{lcccc}
\hline \multicolumn{1}{c}{ Característica } & Norma & Especificação & Unidade & Resultados \\
\hline PENETRAÇÃO & DNIT 155/2010 & 30 a 45 & $0,1 \mathrm{~mm}$ & 32 \\
PONTO DE AMOLECIMENTO & DNIT 131/2010 & 52 min & grau C & 54 \\
VISCOSIDADE BROOKFIELD 135 GC-SP21 20 RPM & NBR 15184:2004 & 374 & Cp & 597,5 \\
VISCOSIDADE BROOKFIELD 150 GC-SP21 & NBR 15184:2004 & 203 & Cp & 287,5 \\
VISCOSIDADE BROOKFIELD 177 GC-SP21 & NBR 15184:2004 & 76 a 285 & Cp & 112,5 \\
PONTO DE FULGOR & NBR 11341:2014 & 235 min & grau C & 335 \\
AQUECIMENTO A 177 GC & DNIT 095/2006 & NESP & Não se aplica & NESP \\
ÍNDICE DE SUSCEPTIBILIDADE TÉRMICA & DNIT 095/2006 & $-1,5$ a 0,7 & Não se aplica & $-1,2$ \\
\hline
\end{tabular}

Fonte: Elaborada pelo autor (2019).

\subsection{BORRACHA MOÍDA}

Este tópico apresenta os resultados de caracterização da borracha moída utilizada neste estudo.

\subsubsection{Granulometria}

$\mathrm{Na}$ tabela 08, apresenta-se o resultado da granulometria individual da borracha. 
Verifica-se que $83,8 \%$ dos grãos de

40. borracha ficam retidos na peneira número

Tabela 08: Granulometria da borracha

\begin{tabular}{|c|c|c|c|c|c|}
\hline Material: & & Borracha Moída & $4 \mathrm{~mm}$ & Peso total da amostra & 221,700 \\
\hline Polegada & Mm & $\begin{array}{c}\text { Peso Retido Por } \\
\text { Peneira }\end{array}$ & $\%$ Retido por peneira & Retida Acumulada & \% Passado \\
\hline 10 & 2 & 0 & $0,0 \%$ & $0,0 \%$ & $100,0 \%$ \\
\hline 40 & 0,42 & 185,7 & $83,8 \%$ & $83,8 \%$ & $16,2 \%$ \\
\hline 80 & 0,18 & 32,4 & $14,6 \%$ & $98,4 \%$ & $1,6 \%$ \\
\hline 200 & 0,075 & 3,5 & $1,6 \%$ & $100,0 \%$ & $0,0 \%$ \\
\hline
\end{tabular}

Fonte: Elaborada pelo autor (2019).

Na tabela 09, apresenta-se a massa específica da borracha no valor de 1,15 $\mathrm{g} / \mathrm{cm}^{3}$, sendo um valor bem inferior se comparado ao do agregado natural, que foi, em média, $2,84 \mathrm{~g} / \mathrm{cm}^{3}$. O valor encontrado utilizado para o cálculo da massa específica efetiva da mistura dos agregados.

Tabela 09: Massa específica

\begin{tabular}{ccccc}
\hline Amostra & $\begin{array}{c}\text { Peso } \\
\text { inicial } \\
(\mathbf{g})\end{array}$ & $\begin{array}{c}\text { Peso } \\
\text { final } \\
(\mathrm{g})\end{array}$ & $\begin{array}{c}\text { Volume de } \\
\text { borracha } \\
(\mathbf{m l})\end{array}$ & $\begin{array}{c}\text { Densida } \\
\mathbf{d e} \\
\mathbf{g} / \mathbf{c m}^{3}\end{array}$ \\
\hline & & & & \\
1 & 120,8 & 126,5 & 5,0 & 1,15 \\
2 & 121,7 & 127,6 & 5,0 & 1,17 \\
& & & & \\
3 & 120,1 & 125,7 & 5,0 & 1,12 \\
\hline
\end{tabular}

\section{Densidade Média $\mathrm{g} / \mathrm{cm}^{3} \quad 1,15$}

Fonte: Elaborada pelo autor (2019).

A massa específica da borracha foi obtida pelo método do deslocamento de fluido (querosene), conforme a pesquisa de (SALINI, 2000), e não possui norma específica para esse procedimento.

\subsection{MASSA ASFÁLTICA}

Neste item, são apresentados os resultados das caracterizações volumétricas e mecânicas das misturas asfálticas estudadas. As misturas com adição de borracha terão os seus parâmetros mecânicos comparados aos da mistura de referência para avaliação de desempenho.

As misturas asfálticas devem obedecer aos limites da norma 031/2006, indicados nas tabelas 10 e 11 .

Tabela 10: Parâmetros volumétricos e mecânicos das misturas

\begin{tabular}{|c|c|c|c|}
\hline Características & $\begin{array}{c}\text { Método de } \\
\text { ensaio }\end{array}$ & $\begin{array}{c}\text { Camada de } \\
\text { rolamento }\end{array}$ & $\begin{array}{c}\text { Camada } \\
\text { de Ligação } \\
\text { (Binder) }\end{array}$ \\
\hline $\begin{array}{c}\text { Porcentagem de } \\
\text { vazios, \% }\end{array}$ & $\begin{array}{c}\text { DNER-ME } \\
043\end{array}$ & 3 a 5 & 4 a 6 \\
\hline $\begin{array}{c}\text { Relação } \\
\text { betume/vazios }\end{array}$ & $\begin{array}{c}\text { DNER-ME } \\
043\end{array}$ & $75-82$ & $65-72$ \\
\hline $\begin{array}{c}\text { Estabilidade } \\
\text { mínima, (Kgf) } \\
\text { (75 golpes) }\end{array}$ & $\begin{array}{c}\text { DNER-ME } \\
043\end{array}$ & 500 & 500 \\
\hline $\begin{array}{c}\text { Resistência à } \\
\text { Tração por } \\
\text { Compressão }\end{array}$ & $\begin{array}{c}\text { DNER-ME } \\
138\end{array}$ & 0,65 & 0,65 \\
$\begin{array}{c}\text { Diametral estática } \\
\text { a 25 }{ }^{\circ} \mathrm{C}\end{array}$ & & \\
\hline
\end{tabular}

Fonte: DNIT (2006). 
Na tabela 11, mostra-se o parâmetro de resultado dos vazios do agregado mineral de acordo com o diâmetro máximo do agregado utilizado na mistura asfáltica.

\begin{tabular}{|c|c|c|}
\hline $11^{\prime \prime}$ & 38,1 & 13 \\
$1^{\prime \prime}$ & 25,4 & 14 \\
$3 / 4^{\prime \prime}$ & 19,1 & 15 \\
$1 / 2^{\prime \prime}$ & 12,7 & 16 \\
$3 / 8^{\prime \prime}$ & 9,5 & 18 \\
\hline
\end{tabular}

Na tabela 12, mostra-se o resumo de

Tabela 11: Vazios do agregado mineral

\begin{tabular}{|c|c|c|}
\hline \multicolumn{3}{|c|}{ VAM - Vazios do Agregado Mineral } \\
\cline { 1 - 2 } Tamanho Nominal Máximo do agregado & \multirow{2}{*}{ VAM Mínimo } \\
\hline \# & $\mathrm{mm}$ & $\%$ \\
\hline
\end{tabular}
todos os resultados dos parâmetros volumétricos e mecânicos das dosagens de referência e com borracha moída.

Fonte: DNIT (2006).

Tabela 12: Parâmetros das misturas

\begin{tabular}{|c|c|c|c|c|}
\hline Teor de Borracha & $\mathbf{0 \%}$ & $1 \%$ & $2 \%$ & $3 \%$ \\
\hline Teor Ótimo de Betume (\%) & 4,5 & 4,5 & 5,0 & 5,0 \\
\hline Massa Esp. Aparente $\left(\mathrm{kg} / \mathrm{m}^{3}\right)$ & 2500,2 & 2468,8 & 2414,1 & 2389,1 \\
\hline Massa Esp. Teórica $\left(\mathrm{kg} / \mathrm{m}^{3}\right)$ & 2628,1 & 2594,5 & 2542,7 & 2511,4 \\
\hline Volume de Vazios - Vv (\%) & 4,9 & 4,8 & 5,1 & 4,9 \\
\hline Vazios Cheios de Betume - VCB (\%) & 10,7 & 10,5 & 11,5 & 11,3 \\
\hline Vazios do Agregado Mineral - VAM (\%) & 15,5 & 15,4 & 16,5 & 16,2 \\
\hline Relação Betume Vazios - RBV (\%) & 68,7 & 68,5 & 69,4 & 70,0 \\
\hline Estabilidade (Kgf) & 1566,3 & 1567,9 & 1382,4 & 770,2 \\
\hline Resistência à Tração (Mpa) & 1,40 & 1,41 & 0,78 & 0,58 \\
\hline
\end{tabular}

Fonte: Elaborada pelo autor (2020). 


\subsection{ANÁLISE ESTABILIDADE E RESISTÊNCIA À TRAÇÃO}

Este item apresenta o comportamento das estabilidades e das resistências à tração encontradas em todas as misturas dosadas.

\subsubsection{Estabilidade}

A mistura de referência com $0 \%$ (zero) por cento de borracha moída apresentou um valor da estabilidade Marshall de 1566,3 Kgf. Na mistura experimental com $1 \%$ (um) por cento de borracha houve um acréscimo da estabilidade em relação à mistura de referência e apresentou o valor de 1567,9 Kgf. Para as misturas com $2 \%$ (dois) por cento e $3 \%$ (três) por cento de borracha, a estabilidade decresceu, e os valores encontrados foram de 1382,4 Kgf e 770,2 Kgf, respectivamente. Constata-se no gráfico 02, que as estabilidades em $\mathrm{Kgf}$ diminuíram para as misturas com teores acima de $1 \%$ de borracha. Apesar de os valores terem diminuídos, ficaram acima de $500 \mathrm{Kgf}$ que é o limite mínimo exigido pela norma DNIT 031/2006.

Gráfico 02: Estabilidade das misturas(kgf)

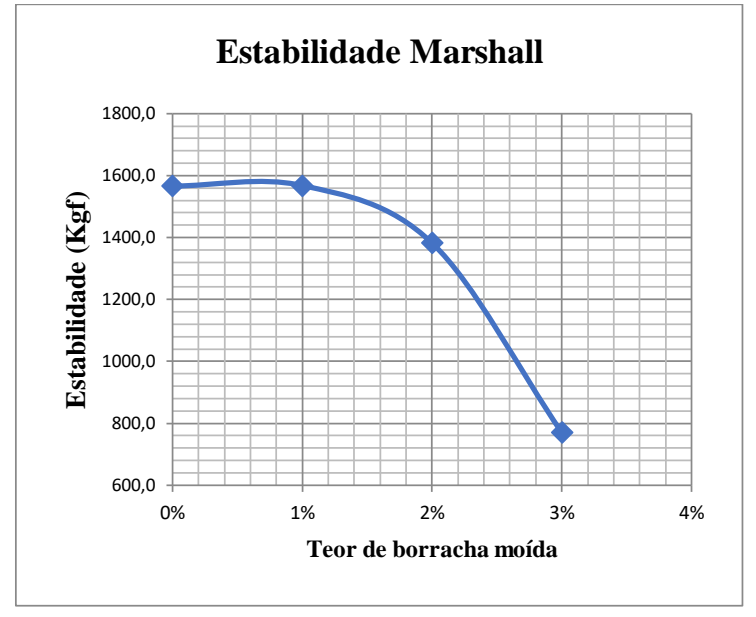

Fonte: Elaborado pelo autor (2019).

\subsubsection{Resistência à tração}

A mistura de referência com $0 \%$ (zero) por cento de borracha moída apresentou um valor de resistência à tração de 1,4 MPa. Na mistura experimental com $1 \%$ (um) por cento de borracha houve um pequeno acréscimo da resistência à tração em relação à mistura de referência e apresentou o valor de 1,41 MPa. Para as misturas com $2 \%$ (dois) por cento e $3 \%$ (três) por cento de borracha, a resistência à tração decresceu drasticamente, e os valores encontrados foram de 0,78 MPa e 0,58 Mpa, respectivamente. Deve-se salientar que apenas a mistura experimental com 3\% (três) por cento de borracha apresentou um valor abaixo do valor mínimo exigido por norma, que é de 0,68 $\mathrm{MPa}$. No gráfico 03, evidenciou-se o comportamento das misturas à medida que aumentou a quantidade de borracha moída. 
Gráfico 03: Resistência à tração

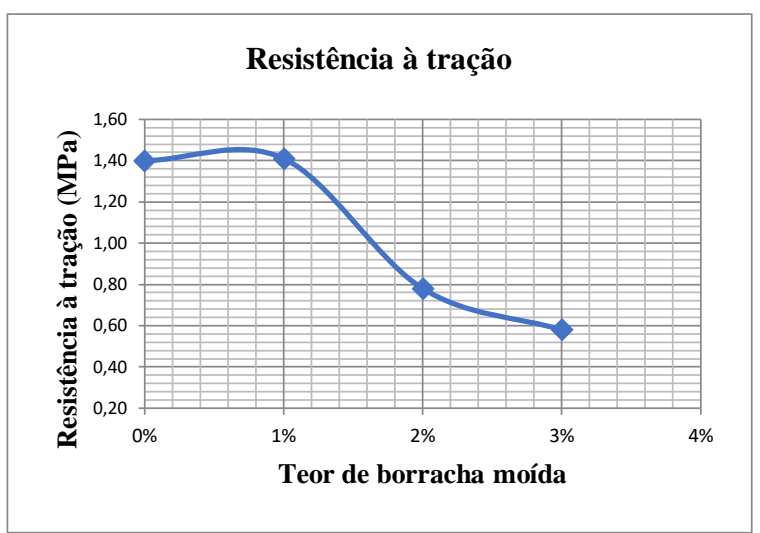

Fonte: Elaborado pelo autor (2019).

Portanto, à medida que aumentou a quantidade de borracha nas misturas acima de $1 \%$, a resistência à tração diminuiu.

\section{CONCLUSÕES}

Para as dosagens de todas as misturas asfálticas, foram analisados os parâmetros volumétricos estabelecidos pela norma DNIT 031/2006. Foi utilizado como critério principal para escolha do teor ótimo de ligante o volume de vazios.

A mistura de referência ficou com $4,9 \%$ de vazios e $4,5 \%$ de teor ótimo de betume, e todos os demais parâmetros enquadraram-se na norma DNIT 031/2006.

A mistura experimental com $1 \%$ de borracha moída ficou com $4,8 \%$ de vazios e com $4,5 \%$ de teor ótimo de betume. De acordo com a tabela 12, essa foi a mistura que apresentou as melhores características mecânicas e volumétricas para o emprego na pavimentação.

A mistura experimental com $2 \%$ de borracha moída ficou com todos os parâmetros mecânicos e volumétricos dentro da norma DNIT 031/2006, porém a resistência à tração ficou bem próxima do valor mínimo exigido pela norma.

A mistura experimental com $3 \%$ de borracha moída ficou com todas as características volumétricas dentro dos parâmetros exigidos pela norma DNIT 031/2006. A estabilidade Marshall deu um valor próximo ao limite exigido pela norma, enquanto a resistência à tração deu abaixo do limite mínimo exigido por norma.

Foi observado que, à medida que aumentou a quantidade de borracha nas misturas, a estabilidade e a resistência à tração diminuíram. Segundo Salini (2000), esse fenômeno pode ser explicado pela diminuição da viscosidade da mistura asfáltica após o aumento do emprego da borracha moída, e, devido a esse fato, ela se deforma mais rapidamente, oferecendo menor resistência à aplicação de cargas. Para se efetuar uma comparação em termos de paridade, seria necessário ajustar a velocidade de aplicação da carga de acordo com a viscosidade da mistura, levando em conta os diferentes percentuais de borracha inseridos.

Sendo assim, este estudo procurou avaliar os efeitos da substituição de parte do agregado miúdo por borracha moída para misturas asfálticas densas, e foi evidenciado que a mistura experimental com $1 \%$ foi a que obteve o melhor desempenho em todos os requisitos exigidos pela norma DNIT 031/2006 e é a mais adequada ao uso na pavimentação.

Seguem algumas sugestões para novas pesquisas:

1. Avaliar a inserção de diferentes teores de borracha sem a exclusão de agregados minerais.

2. Avaliar o impacto do tempo de digestão da borracha.

3. Realizar um estudo inserindo a borracha em temperatura ambiente na mistura asfáltica, para simular a situação real da usina.

4. Realizar um estudo com diferentes granulometrias de borracha moída.

5. Avaliar a utilização de borrachas em outros tipos de misturas asfálticas. 
6. Avaliar o melhor local para a inserção da borracha moída na usina de asfalto de forma segura.

\section{AGRADECIMENTOS}

Ao professor doutor Ronaldo Feu Rosa Pacheco, pelo apoio.

\section{REFERÊNCIAS}

ASSOCIAÇÃO BRASILEIRA DE NORMAS TÉCNICAS. NBR 6023:

informação e documentação - referências elaboração. Rio de Janeiro, 2002. 24 p.

.NBR 6296: Produtos betuminosos semissólidos - Determinação da massa específica e densidade relativa. Rio de Janeiro, 2012. 6p.

.NBR 9935: Agregados -

Terminologia. Rio de Janeiro, 2011. 12p.

NBR 11341: Derivados de petróleo -

Determinação dos pontos de fulgor e de combustão em vaso aberto Cleveland. Rio de Janeiro, 2015. 18p.

.NBR 15184: Materiais betuminosos -

Determinação da viscosidade em temperaturas elevadas usando um viscosímetro rotacional. Rio de Janeiro, 2005. 4p.

BERNUCCI, Liedi Bariani; MOTTA, Laura Maria Goretti da; CERATTI, Jorge Augusto Pereira; SOARES, Jorge Barbosa.

Pavimentação asfáltica: Formação básica para engenheiros. Rio de janeiro:

PETROBRÁS - ABEDA, 2008.

BERTOLLO, Sandra A. Margarido. Avaliação Laboratorial de mistura asfáltica densa modificada com adição de
A todo o corpo docente e à Coordenação da Pós-Graduação em Engenharia de Infraestrutura Urbana do IFES Campus Vitória-ES.

borracha. 2002. $252 \mathrm{f}$. Tese (Escola de Engenharia de São Carlos), Universidade de São Paulo, São Carlos, 2002.

BERTOLLO, Sandra A. Margarido; FERNANDES JÚNIOR, José Eleomar, BERNUCCI, Liedi Bariani; MOURA, Edson de. Avaliação Laboratorial de mistura asfáltica densa modificada com adição de borracha. Revista Transportes, p. 65-83, 2002.

COGO, Lisiani Dalenogare. Estudo do comportamento de misturas asfálticas densas modificadas com borracha moída. Alegrete-RS, 2017.

. DAER/RS-EL 108/01 Determinação do índice de lamelaridade. Departamento Autônomo de Estradas de Rodagem. 2001.

DEPARTAMENTO NACIONAL DE INFRA-ESTRUTURA DE TRANSPORTES. NORMA DNIT 031/2006-ES: pavimentos flexíveis Concreto asfáltico - Especificação de serviço. Rio de Janeiro, 2006.

DEPARTAMENTO NACIONAL DE INFRA-ESTRUTURA DE TRANSPORTES. NORMA DNIT 095/2006-EM: Cimentos asfálticos de petróleo - Especificação de material. Rio de Janeiro, 2006. 
DEPARTAMENTO NACIONAL DE

INFRA-ESTRUTURA DE TRANSPORTES. NORMA DNIT

131/2010-ME: Materiais asfálticos -

Determinação do ponto de amolecimento -

Método do Anel e Bola - Método de ensaio.

Rio de Janeiro, 2010.

DEPARTAMENTO NACIONAL DE

INFRA-ESTRUTURA DE

TRANSPORTES. NORMA DNIT

136/2018-ME: Pavimentação asfáltica -

Misturas asfálticas - Determinação da

resistência à tração por compressão

diametral - Método de ensaio. Rio de

Janeiro, 2018.

DEPARTAMENTO NACIONAL DE

INFRA-ESTRUTURA DE

TRANSPORTES. NORMA DNIT

155/2010-ME: Material asfáltico -

Determinação da penetração Método de ensaio. Rio de Janeiro, 2010.

DNER-ME 043/95. Misturas

betuminosas a quente - ensaio Marshall.

Departamento Nacional de Estradas de

Rodagem. 1995.

DNER-ME 054/97. Equivalente de areia. Departamento Nacional de Estradas de Rodagem. 1997

DNER-ME 035/98. Agregados determinação da abrasão "Los Angeles". Departamento Nacional de Estradas de Rodagem. 1998.

DNER-ME 081/98. Agregados determinação da absorção e da densidade de agregado graúdo. Departamento Nacional de Estradas de Rodagem. 1998.

DNER-ME 083/98. Agregados análise granulométrica. Departamento Nacional de Estradas de Rodagem. 1998.

DNER-ME 084/95. Agregado Miúdo - determinação da massa específica real.
Departamento Nacional de Estradas de Rodagem. 1995.

. DNER-ME 085/94. Material

finamente pulverizado - determinação da massa específica real. Departamento Nacional de Estradas de Rodagem. 1994.

DNER-ME 089/94. Agregados avaliação da durabilidade pelo emprego de soluções de sulfato de sódio ou de magnésio. Departamento Nacional de Estradas de Rodagem. 1994.

. DNER-ME 117/94. Mistura betuminosa - determinação da densidade aparente. Departamento Nacional de Estradas de Rodagem. 1994.

. DNER-PRO 120/97. Coleta de amostras de agregado. Departamento Nacional de Estradas de Rodagem. 1997.

. DNER-PRO 199/96. Redução de amostras de campo de agregados para ensaio em laboratório. Departamento Nacional de Estradas de Rodagem. 1996.

FEDERAL HIGHWAY

ADMINISTRATION. Crumb Rubber

Modifier Design Procedures and Construction Practices. Publication $\mathrm{N}^{\circ}$ FHWA-AS-93-011.

HELMANT, Mena; SOULIMAN, I; WALEED Zeiada; MAYZAN Isied. Mechanistic Assessment of Fatigue Performance and Cost Analysis of Pavement Overlays: Comparison between Conventional Hot Mixed Asphalt, Asphalt Rubber, and Polymer Modified Mixture. Texas USA ,2019.

INSTITUTO BRASILEIRO DO MEIO AMBIENTE E DOS RECURSOS NATURAIS RENOVÁVEIS. Relatório de Pneumáticos. Disponível em: <https://www.ibama.gov.br/phocadownload /pneus/relatoriopneumaticos/ibama- 
relatorio-pneumaticos-2017-nov.pdf $>$.

Acesso em: 12 maio 2019.

SALINI, Reus Bortolotto. Utilização de borracha reciclada de pneus em misturas asfálticas. 2000. 139 f. Dissertação (Mestrado em Engenharia Civil) -

SETYAWAN, Ary; FEBRIANTO, Nugroho; SARWONO, Djoko. Design and Properties of Thin Surfacing Hot Mix Asphalt Containing Crumb Rubber as Partial Aggregate Replacement. Civil Engineering Department, Sebelas Maret University, Jl. Ir. Sutami 36 A
Universidade Federal de Santa Catarina, Florianópolis, 2000.

SARTORI, Luan Picinin; LUVIZÃO

Gislaine. Análise de misturas asfálticas tipo CAUQ com adição de resíduo de borracha. Unoesc \& Ciência - ACET, Joaçaba, p. 17-24, Edição Especial, 2014.

Surakarta, Indonesia, 2016.

WANG, Tao; XIAO, F.; XINGYI, Zhu; BAOSHAN, Huang; JINGANG Wang; AMIRKHANIAN, S. Energy consumption and environmental impact of rubberized asphalt pavement, USA (2018) 139-158. 